\title{
Severidade da Podridão-Verde em Inhames e Especialização Fisiológica de Penicillium sclerotigenum*
}

\author{
Idjane S. Oliveira ${ }^{1}$, Edna Dora. M. N. Luz², José Luiz Bezerra ${ }^{2}$, Romero M. Moura ${ }^{3}$, \\ Gustavo R. C. Torres \& Leonor C. Maia ${ }^{4}$
}

${ }^{1}$ Departamento de Ciências Biológicas, Universidade Estadual de Santa Cruz, CEP 45600-000, Ilhéus, BA, e-mail: idjaneoliveira@gmail.com; ${ }^{2}$ Departamento de Agronomia, Área de Fitossanidade, Universidade Federal Rural de Pernambuco, CEP 52171-900, Recife, PE; ${ }^{3}$ Seção de Fitopatologia, CEPEC, CEPLAC, CEP 45650-000, Itabuna, BA; ${ }^{4}$ Departamento de Micologia, Universidade Federal de Pernambuco, CEP 50670-420, Recife, PE

(Aceito para publicação em 20/10/2005)

Autor para correspondência: Idjane Santana de Oliveira

OLIVEIRA, I.S., LUZ, E.D.M.N., BEZERRA, J.L., MOURA, R.M., TORRES, G.R.C. \& MAIA, L.C. Severidade da podridão-verde em inhames e especialização fisiológica em Penicillium sclerotigenum. Fitopatologia Brasileira 31:094098. 2006

\section{RESUMO}

Estudaram-se as reações do inhame Dioscorea alata cv. São Tomé e D. cayennensis cv. Da Costa em relação à severidade da podridão-verde, causada pelo fungo Penicillium sclerotigenum. Ao mesmo tempo, foi pesquisada à ocorrência de especialização fisiológica do agente causal, em relação à patogenicidade, nas mencionadas espécies de inhame. Para complementar esse estudo, analisou-se, in vitro, o crescimento micelial de $P$. sclerotigenum em três meios de cultura semi-sintéticos, sendo dois à base de extrato de túberas das espécies de inhame supracitadas e o terceiro de batata inglesa (Solanum tuberosum), todos complementados com dextrose e ágar. Observou-se que a severidade da podridãoverde foi menor em $D$. alata do que em $D$. cayennensis, não sendo constada especialização fisiológica nos isolados de $P$. sclerotigenum. Corroborando com esses resultados, o crescimento e desenvolvimento dos isolados de P. sclerotigenum no meio D. alata - Dextrose - Ágar foi significativamente menor do que nos meios Batata - Dextrose - Ágar e D. cayennensis - Dextrose - Agar, esses mais favoráveis para crescimento do fungo.

Palavras-chave adicionais: inoculação cruzada, especialização parasitária, crescimento in vitro, Dioscorea alata, D. cayennensis.

\begin{abstract}
Severity of green rot in yellow and water yams and the physiological specialization of Penicillium sclerotigenum

The degree of green rot severity was evaluated in two yam species, D. alata and D. cayennensis. The causal agent of this disease is the fungus Penicillium sclerotigenum, a highly virulent pathogen on D. cayennensis in the producing areas all over the world. In addition, by cross inoculation, an investigation was conducted on the occurrence of physiological adaptations of the fungus relative to its pathogenicity on these species of yams. To complement this study the mycelial growth of $P$. sclerotigenum was evaluated on three culture media, two based on extracts of the yam species examined and the other one on potato (Solanum tuberosum). Dextrose and agar were added to all cultures. The results showed that green rot was less severe on $D$. alata than on D. cayennensis. No physiological adaptation in relation to the pathogenicity of $P$. sclerotigenum to both yam species was found. Potato-dextrose-agar and $D$. cayennensis-dextrose-agar were the best substrates for $P$. sclerotigenum development and growth.
\end{abstract}

Additional keywords: cross inoculation, pathogenic especialization, in vitro growth, Dioscorea alata, D. cayennensis.

A cultura do inhame da costa (Dioscorea cayennensis Lam.) é de alta significância econômica para o Nordeste, pois sua túbera comercial, exportada para os Estados Unidos e países da Europa, possui preço estável no mercado interno, mesmo com alta demanda, e é consumida por todas as classes sociais (Santos, 1996; Mesquita, 2002). Dois tipos de inhame têm destaque no mercado brasileiro: o inhame da costa, único utilizado nas exportações, e o São Tomé (D. alata L.), este

\footnotetext{
* Parte da Tese de Doutorado do primeiro autor apresentada ao Curso de
} Pós-Graduação em Ciências Biológicas, UFPE, PE (2005) menos cultivado na região. No Nordeste, problemas fitossanitários, especialmente nematóides e fungos, dificultam grandemente o cultivo do inhame da costa (Moura, 2005, Ritzinger et al., 2003). Uma doença epidêmica, de alta severidade e de etiologia ainda desconhecida, denominada requeima, torna o cultivo do inhame São Tomé, único suscetível ao mal, um investimento de alto risco econômico na Região. Não foram encontradas referências bibliográficas que explicassem a restrição da requeima ao cultivo do inhame São Tomé.

O parasitismo dos fitonematóides Meloidogyne 
incognita (Kofoid \& White) Chitwood, M. javanica (Treub) Chitwood, Pratylenchus coffeae Filipjev \& Stekhoven e Scutellonema bradys (Steiner \& Le Hew) Andrassy é comum em plantios de inhame da costa em todas as áreas de produção do Nordeste e em países africanos e caribenhos, sempre promovendo perdas significativas (Acosta \& Ayala, 1975; Jatala \& Bridge, 1990; Moura, 2005). Esses organismos, que possuem hábitos parasitários e hospedeiros distintos, evidenciam diferenças fisiológicas entre as duas espécies do gênero Dioscorea em questão. O inhame da costa é altamente suscetível a esses fitonematóides, enquanto a cultivar São Tomé mostra-se aparentemente imune, pois nunca houve registro de ocorrência de nematose nesse genótipo no Brasil (Moura, 2005). A literatura internacional reporta suscetibilidade de $D$. alata em relação a esses nematóides sem mencionar, entretanto, o nome da cultivar (Jatala \& Bridge, 1990). Por outro lado, observações realizadas em túberas de inhame da costa em armazenamento no Nordeste têm revelado ser essa cultivar altamente suscetível à podridão-verde, doença de alta incidência e severidade, que se inicia sempre por ferimentos, na maioria resultante do parasitismo dos fitonematóides, e das práticas inerentes à colheita, limpeza e transporte (Moura et al., 1976). No local do ferimento, após a penetração do patógeno e início da infecção, forma-se uma área de consistência aquosa, externa, que evolui internamente para uma lesão circular, profunda, de coloração marrom e consistência úmida (Figura $1 \mathrm{G})$. Na parte externa correspondente, após alguns dias do início da infecção, forma-se um denso e vigoroso micélio verde que mais tarde pode produzir abundante quantidade de esclerócios. No inhame São Tomé a patogênese ocorre de modo semelhante, mas a evolução da lesão é lenta, possibilitando a hospedeira limitá-la pela formação de tecidos corticosos (Figura 1I). A podridão-verde, que ocorre apenas durante o armazenamento, tem como agente etiológico o fungo Penicillium sclerotigenum Yamamoto, relatado no Brasil por Moura et al. (1976) em túberas comerciais e sementes de Dioscorea spp. Acredita-se que a natureza da reação diferenciada dos dois inhames em relação aos citados patógenos possa ser de origem morfológica, como espessura da epiderme da túbera, por exemplo, ou fisiológica, pela presença de substâncias químicas presentes, ou produzidas em resposta à infecção.

Com base nessas informações, os objetivos deste estudo foram verificar, por meio de inoculações artificiais, o grau de severidade da podridão-verde no inhame São Tomé, comparativamente ao inhame da costa, e, ao mesmo tempo, verificar a possível existência de especialização fisiológica em $P$. sclerotigenum, por meio de testes de patogenicidade cruzada, de acordo com os conceitos de Agrios (1997). Além disso, foi estudado o crescimento micelial de $P$. sclerotigenum em meios de cultura semi-sintético, dois dos quais contendo, como fonte de carbono, extratos de túberas de inhame D. alata e D. cayennensis, para confirmar o restritivo desenvolvimento de $P$. sclerotigenum em $D$. alata, em condições naturais.
Neste estudo, foram utilizados quatro isolados de $P$. sclerotigenum: dois originários de D. alata (RO 1 e RO 9) e dois de D. cayennensis (BA 30 e DF 2), selecionados aleatoriamente a partir de uma coleção com 50 isolados, obtidos em sete Estados brasileiros. Em laboratório, os isolados foram mantidos em meio CYA (Czapek Yeast Autolysate Agar), segundo Pitt (1988), identificados ao nível de espécie, de acordo com Samson \& Frisvad (2004) e depositados na Coleção de Culturas Fúngicas (Micoteca URM) do Departamento de Micologia, Universidade Federal de Pernambuco, com os seguintes registros: RO1 (5041 URM), RO9 (5040 URM), BA30 (5043 URM) e DF2 (5042 URM). Todos eram comprovadamente patogênicos, conforme testes de inoculação nas espécies de inhame de origem e provenientes de três estados: Rondônia (RO 1 e RO 9), Bahia (BA 30) e Distrito Federal (DF 2). Antes da pesquisa, observou-se que os isolados apresentavam-se morfologicamente similares e possuíam aspectos culturais em comum, a saber, bom crescimento nos meios de identificação de espécies do gênero Penicillium, que são o CYA, MEA (Malt Extract Autolysate Agar) e YES (Yeast Extract Sucrose Agar), segundo Samson \& Frisvad (2004), e abundante quantidade de esclerócios, característica típica da espécie.

Para avaliar o grau da severidade da podridão-verde em $D$. alata e $D$. cayennensis foram realizadas inoculações com os quatro isolados em ambas espécies. Para tal, túberas comerciais foram selecionadas visualmente quanto ao tamanho, idade e sanidade. Em laboratório, foram lavadas com água e sabão, desinfetadas com álcool a 70\%, e secas à temperatura ambiente. As inoculações foram executadas após a realização de uma delicada incisão circular sobre a cutícula, com um vazador metálico, de aproximadamente $1 \mathrm{~cm}$ de diâmetro, nas regiões basal, intermediária e de crescimento. No centro desses pequenos círculos formados pela incisão, foram depositados $50 \mu \mathrm{l}$ de uma suspensão de conídios, contendo $10^{7}$ unidades $/ \mathrm{ml}$, em água destilada esterilizada, sendo adicionado $0,01 \%$ de Tween 80 . Seguiu-se a incubação em câmara úmida individual, em saco plástico negro para redução da luminosidade. O mesmo tipo de tratamento, porém, omitindo-se o fungo, foi utilizado como testemunha. O delineamento estatístico foi do tipo inteiramente casualizado com seis tratamentos e cinco repetições. O experimento permaneceu em condições ambientais de laboratório, com temperatura de $28 \pm 2{ }^{\circ} \mathrm{C}$, por 21 dias, quando se avaliou a severidade da podridão-verde e a virulência dos isolados. Para tal, removeu-se a casca entre os pontos de inoculação, do modo mais uniforme possível, para observação da área necrosada interna, que é naturalmente circular (Figura 1A - E). Em seguida, em cada túbera, nos três locais de inoculação, tomaram-se as medidas de dois diâmetros perpendiculares, com uma régua milimétrica, estabelecendo-se, ao final, a média dos diâmetros das lesões da túbera. A profundidade foi medida após corte transversal passando no centro da lesão. A severidade foi estabelecida mediante o cálculo do volume 
de um cilindro, formado por tecidos necrosados, tomandose a área da lesão como base e a profundidade como a altura do cilindro, avaliando-se, ao final, as medidas da profundidade, áreas, e volume das lesões, por meio das respectivas fórmulas geométricas. Os dados referentes às citadas variáveis foram submetidos à análise de variância e as médias comparadas pelo teste de Tukey $(P<0,05)$.

Para o estudo comparativo de crescimento radial do micélio nos diferentes meios de cultura, os isolados RO $1 \mathrm{e}$ DF 2 foram plaqueados nos três meios de cultura semisintéticos, contendo diferentes fontes naturais de carbono, duas das quais extrato de túberas de D. alata e D. cayennensis e a terceira de batata inglesa (Solanum tuberosum L). Os meios testados foram: D. alata-dextrose-agar (DADA), D. cayennensis-dextrose-agar (DCDA) e Batata-dextrose-agar (BDA); sendo $200 \mathrm{~g}$ de inhame ou batata, $20 \mathrm{~g}$ de dextrose e $20 \mathrm{~g}$ de ágar, em 11 de água destilada. Cultivou-se o fungo em placas de Petri, contendo $25 \mathrm{ml}$ de meio, mantidos à temperatura de $28 \pm 2{ }^{\circ} \mathrm{C}$, sob luz natural com cinco repetições. As aferições dos diâmetros das colônias foram feitas com a mesma régua milimetrada, a cada dois dias, durante oito dias. $\mathrm{O}$ experimento foi conduzido segundo delineamento do tipo inteiramente casualizado, em arranjo fatorial $3 \times .2$ (três meios $\times$ dois isolados). Modelos lineares, logarítmicos e quadráticos foram testados na tentativa de descrever o crescimento micelial dos isolados RO1 e DF2 nos três meios anteriormente citados.

Os resultados demonstraram que as duas espécies de

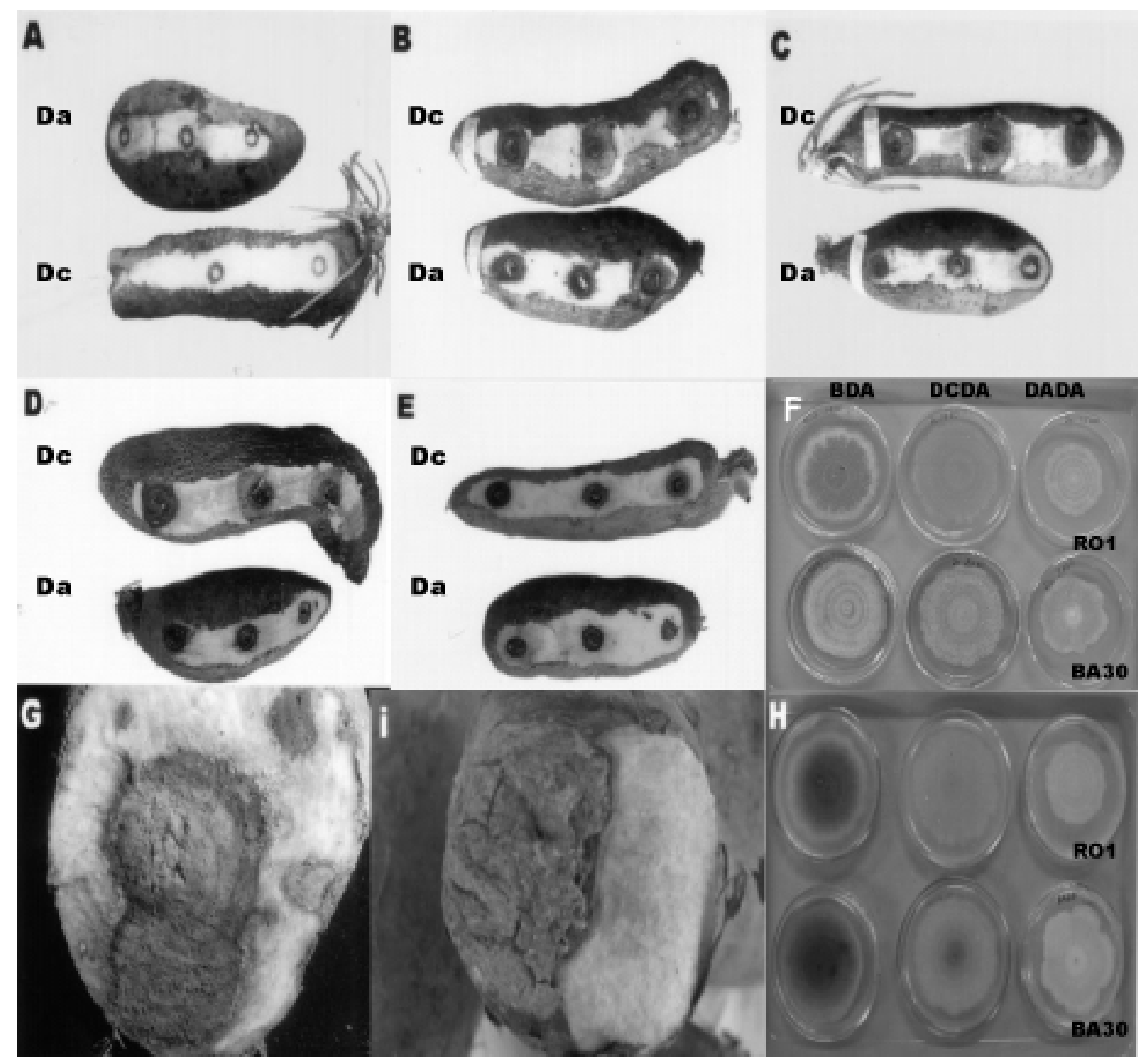

FIG. 1 - Severidade da podridão-verde do inhame (Dioscorea cayennensis) em túberas comerciais, 21 dias após as inoculações cruzadas, com isolados de Penicillium sclerotigenum em D. cayennensis $(\mathrm{Dc})$ e D. alata $(\mathrm{Da})(\mathrm{A}-\mathrm{E})$. A = Testemunha de Dc e Da; B = RO1; C = RO 9; D = BA30; E = DF2. F = Colônias de P. sclerotigenum em três meios de cultura. G = Infecção natural de $P$. sclerotigenum em $D$. cayennensis mostrando a expansão da lesão. $\mathrm{H}$ = Reverso das colônias de BA30 e RO1, enfatizando a produção de pigmento marrom nos meios de cultura BDA e DCDA e ausência em DADA. I = Infecção natural de P. sclerotigenum em D. alata mostrando a lesão restrita. 
inhame foram suscetíveis à podridão-verde, sendo a doença mais severa em D. cayennensis do que em D. alata (Tabela 1). Não foi constatada especialização fisiológica entre os isolados oriundos das duas espécies de inhame, pois os resultados das inoculações cruzadas mostraram-se positivos, ocorrendo apenas variações quanto à severidade da doença e virulência dos isolados (Tabela 1) que foram agressivos, infetando as duas espécies de inhame. Entretanto, DF2 foi o menos virulento e BA 30, RO 1 e RO 9 os mais virulentos em D. cayennensis, a considerar os conceitos de van der Plank (1967) (Tabela 1). Conforme visto, BA 30 e DF 2, bem como RO 1 e RO 9 eram oriundos de D. cayennensis e D. alata respectivamente, indicando que independentemente da origem dos isolados, a severidade da podridão-verde foi maior em D. cayennensis do que em D. alata. Em D. alata, também independentemente da origem não houve diferença significativa entre os isolados quanto à virulência (Tabela 1).

Com relação ao crescimento do fungo nos três meios de cultura não foi verificada interação significativa entre isolados e meios de cultura. Penicillium sclerotigenum desenvolveu-se melhor em BDA, seguido por DCDA e DADA, sendo o modelo linear o que mais se adequou para descrever o crescimento micelial dos dois isolados estudados (RO 1 e DF 2) nos três meios testados (Figura 2). Ademais, ainda com relação ao desenvolvimento micelial em meio de cultura, pôde-se observar que $P$. sclerotigenum em BDA (Figura 1F) formou colônias com aspecto típico da espécie, com abundante presença de esclerócios, produzidos após cinco dias de crescimento. Houve alta produção de pigmento marrom solúvel no meio BDA, pouca em DCDA e ausência em DADA (Figura 1H). No meio DADA, o micélio desenvolveu-se lentamente, mostrando-se escasso, pouco denso e com produção retardada de esclerócios, observada apenas após 40 dias de cultivo. Esses resultados podem ter relação com o fato da podridão-verde ser mais rara e de progresso mais lento em $D$. alata em condições naturais (Figura 1I).

Observou-se que as túberas de D. alata constituem substrato pouco favorável ao desenvolvimento de $P$. sclerotigenum. A explicação para essa diferença fisiológica entre as duas espécies de Dioscorea poderá estar no conteúdo de sacarose presente nas suas túberas. Ogundana et al. (1971), observaram que P. sclerotigenum, Botryodiplodia theobromae Pat. e Aspergillus niger Tiegh., causadores de

TABELA 1 - Severidade da podridão-verde do inhame (Dioscorea cayennensis) por meio de inoculações cruzadas, utilizando-se quatro isolados de Penicillium sclerotigenum, sendo dois obtidos de D. cayennensis (BA 30 e DF 2) e dois de $D$. alata (RO 1 e RO 9)

\begin{tabular}{|c|c|c|c|c|c|c|c|c|}
\hline \multirow{2}{*}{$\begin{array}{l}\text { Isolado de } \\
\text { Penicillium sclerotigenum }\end{array}$} & \multicolumn{2}{|c|}{ Diâmetro da lesão } & \multicolumn{2}{|c|}{ Profundidade da lesão } & \multicolumn{2}{|c|}{ Área da lesão $\left(\mathrm{cm}^{2}\right)$} & \multicolumn{2}{|c|}{ Volume da lesão $\left(\mathrm{cm}^{3}\right)$} \\
\hline & DC & DA & DC & DA & DC & DA & DC & DA \\
\hline BA30 & 3,10 a A & $1,39 \mathrm{~b} \mathrm{~A}$ & 2,74 a A & $2,01 \mathrm{~b} \mathrm{~B}$ & 7,74 a A & $1,54 \mathrm{~b} \mathrm{~A}$ & 21,13 a A & $3,06 \mathrm{~b} \mathrm{~A}$ \\
\hline DF2 & 1,88 a B & 1,48 a A & 2,01 a B & 1,72 a B & 2,80 a B & 1,77 a $\mathrm{A}$ & 5,61 a B & 3,04 a A \\
\hline RO1 & 3,27 a $\mathrm{A}$ & $1,90 \mathrm{~b} \mathrm{~A}$ & 2,16 a B & 2,18 a $\mathrm{AB}$ & 8,70 a $\mathrm{A}$ & $2,94 \mathrm{~b} \mathrm{~A}$ & 18,74 a A & $6,49 \mathrm{~b} \mathrm{~A}$ \\
\hline RO9 & $2,81 \mathrm{a} \mathrm{A}$ & $1,69 \mathrm{~b} \mathrm{~A}$ & $2,47 \mathrm{a} \mathrm{AB}$ & $2,65 \mathrm{a} A$ & 6,45 a A & $2,30 \mathrm{~b} \mathrm{~A}$ & 15,92 a A & $6,11 \mathrm{~b} \mathrm{~A}$ \\
\hline
\end{tabular}

Na mesma linha, onde se compara severidade da doença (área e profundidade isoladamente), médias seguidas da mesma letra minúscula e na mesma coluna, onde se compara a virulência dos isolados em $D$. cayennensis e $D$. alata, médias seguidas por letras maiúsculas, não diferem estatisticamente ao nível de $\mathrm{P}<0,05$ pelo teste de Tukey. $\mathrm{DC}=$ Dioscorea cayennensis. $\mathrm{DA}=$ Dioscorea alata .
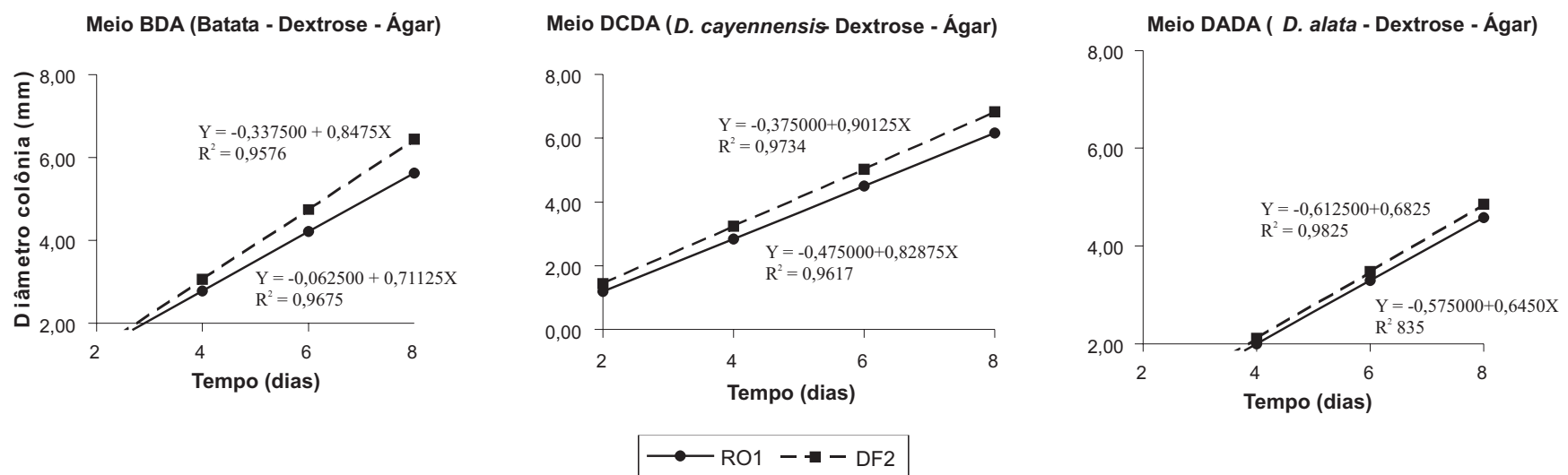

FIG. 2 - Representação pelo modelo linear do crescimento micelial de dois isolados de Penicillium sclerotigenum em três meios de cultivo: BDA, DCDA e DADA. 
podridão de túberas de inhame na Nigéria, utilizaram sacarose mais adequadamente para seu crescimento em meio líquido (peso seco de micélio) do que outros açucares (maltose, glicose e frutose). Os referidos autores constataram também que $D$. cayennensis possui maior teor de sacarose por peso seco em discos de túberas $(0,0084 \mathrm{mg} / \mathrm{g})$ do que $D$. alata $(0,0050 \mathrm{mg} / \mathrm{g})$. Estudo semelhante com outras espécies do gênero Penicillium foi desenvolvido por Stange et al. (2002) ao pesquisarem os efeitos de extratos de casca de citros (Citrus spp.) acrescentados ao meio BDA, em relação ao crescimento de $P$. italicum Wehmer, $P$. digitatum Sacc. e $P$. expansum Link. Os autores concluiram que $P$. digitatum e P. italicum são fisiologicamente adaptados para crescerem na presença dos muitos compostos bioativos produzidos na casca de citros, sendo esses compostos estimulantes de crescimento, enquanto que $P$. expansum não conseguiu se desenvolver bem, nessa condição. Estes autores afirmaram ainda que a maioria das espécies patogênicas de Penicillium possui limitada gama de hospedeiros, sugerindo a existência de adaptação patogênica para cada espécie do fungo à determinada espécie de planta. É possível que esta adaptação possa explicar a pouca susceptibilidade de $D$. alata a $P$. sclerotigenum. Informações dessa natureza precisam ser pesquisadas para subsidiar estudos de melhoramento genético dessas dioscoreáceas na busca de cultivares resistentes à podridão-verde, principal causa de perdas de túberas comerciais e sementes durante o transporte e armazenamento.

\section{REFERÊNCIAS BIBLIOGRÁFICAS}

ACOSTA, N.A. \& AYALA, A. Pathogenicity of Pratylenchus coffeae, Scutellonema bradys, Meloidogyne incognita e Rotylenchulus reniformis on Dioscorea rotundata. Journal of Nematology 7:1-15. 1975.
AGRIOS, G. Plant Pathology. Academic Press. New York. 1997. JATALA, P.I. \& BRIDGE, J. Nematode parasites of root and tuber crops. In: Luc, M., Sikora, R.A. \& Bridge, J. (Eds.) Plant Parasitic Nematodes in Subtropical and Tropical Agriculture. CAB International, Oxon, UK. 1990. pp.123-129.

MESQUITA, A.S. Inhame - Dioscorea cayennennsis Lam. e taro Colocasia esculenta (L.) Schott.- Cenários dos mercados brasileiro e internacional. In: Anais. II Simpósio Nacional sobre as Culturas do Inhame e do Taro. II SINCIT, João Pessoa, Paraíba, 1:215-238. 2002.

MOURA, R.M., RIBEIRO, G.P. COELHO, R.S.B. \& SILVA JÚNIOR, J.N. Penicillium sclerotigenum Yamamoto, principal fungo causador de podridão em túbras de inhame (Dioscorea cayennensis Lam.), no estado de Pernambuco (Brasil). Fitopatologia Brasileira 1:67-78. 1976.

MOURA, R.M. Doenças do Inhame. In: Kimati, H., Amorim, L., Bergamin Filho, A., Camargo, L.E.A \& Resende, J.A.M. (Eds.) Manual de Fitopatologia. São Paulo, Editora Agronômica Ceres. 2005. pp.415-419.

OGUNDANA, S.K., NAQVI, S.H.Z. \& EKUNDAYO, J.A. Studies on soft rot of yams in storage. Transation British of Mycological Society 56:73-80. 1971.

PITT, J.I.A Laboratory Guide to Common Penicillium Species. CSIRO, Food Research Laboratory, North Ryde, Austrália. 1988.

RITZINGER, C.H.S., SANTOS FILHO, H.P., ABREU, K.C.L.M., FANCELLI, M. \& RITZINGER, R. Aspetos Fitossanitários da Cultura do Inhame. EMBRAPA, Documentos, Cruz das Almas. 2003.

SAMSON, R.A. \& FRISVAD, J.C. Penicillium subgenus Penicillium: new taxonomic schemes and mycotoxins and other extrolites. Studies in Mycology 49:260. 2004.

SANTOS, E.S. Inhame (Dioscorea spp.): Aspectos Básicos da Cultura. João Pessoa: EMEPA-PB, SEBRAE, 1996.

STANGE, R.R., MIDLAND, S.L., SIMS, J.J. \& MCCOLLUM, T.G. Differential effects of citrus peel extracts on growth of Penicillium digitatum, P. italicum and P. expansum. Physiological and Molecular Pant Pathology 61:303-311. 2002. 